\title{
Colocação pronominal no Português do Brasil: a contribuição de estudos de percepção auditiva
}

\author{
The position of pronominal clitics in Brazilian Portuguese: \\ the contribution of language perception investigation \\ Silvia Rodrigues Vieira \\ Cristina Marcia Monteiro de Lima Corrêa \\ Universidade Federal do Rio de Janeiro - Rio de Janeiro - Rio de Janeiro - Brasil
}

$\diamond$

\begin{abstract}
Resumo: Este artigo objetiva trazer evidências - da análise comparativa de investigações sobre a ordem dos clíticos pronominais baseadas na Sociolinguistica Variacionista e na Fonologia Experimental (VIEIRA, 2002; CORRÊA, 2009; 2012) - da contribuição de estudos que conjugam a descrição de dados de produção e percepção linguísticas, auxiliada pela ressíntese da fala. Associando metodologias, as pesquisas mostram que é possível definir (i) a direção fonológica dos pronomes átonos, à direita (como sílabas pretônicas) ou à esquerda (como sílabas postônicas); (ii) os parâmetros acústicos responsáveis por essa direção; e, consequentemente, precisar, em termos sociofonéticos, as características associadas a certas estruturas e variedades.
\end{abstract}

Palavras-chave: Percepção; Cliticização; Sociofonética

\begin{abstract}
This paper aims to bring evidence - from the comparative analysis of investigations about the order of pronominal clitics based on Variationist Sociolinguistics and Experimental Phonology (VIEIRA, 2002; CORREAA, 2009; 2012) - of the contribution of studies that combine description of linguistic production and perception, aided by speech resynthesis. Associating methodologies, the researches show that it is possible to define (i) the phonological direction of the unstressed pronouns, to the right (like pretonic syllables) or to the left (like posttonic syllables); (ii) the acoustic parameters responsible for this direction; and, consequently, to specify, in sociophonetic terms, the characteristics which can be associated with certain structures and varieties.
\end{abstract}

Keywords: Perception; Cliticization; Sociophonetics

\section{Apresentando a questão}

No vasto campo dos interesses relacionados à investigação científica acerca da percepção, por si só pouco desenvolvida nos estudos brasileiros, figura o ainda menos explorado componente acústico ou prosódico como elemento relevante, em termos perceptuais, para a identificação, o condicionamento de variantes linguísticas ou, ainda, sua relação com a caracterização de variedades do português. Embora não poucas vezes se testem - por meio da observação dos usos, na produção dos enunciados - hipóteses de cunho fonético para a explicação de fenômenos variáveis, não se dispõe, ao que parece, de experimentação suficiente de instrumentos para a detecção dos supostos efeitos da recepção e da avaliação do indivíduo em relação ao que ouve, percebe e interpreta, quanto à configuração específica de certa regra variável e/ou quanto ao perfil da comunidade de fala que as variantes possivelmente representam.

Considerando um tema bastante conhecido no que se refere à caracterização de variedades do português, a ordem variável dos clíticos pronominais (pré-verbal/ proclítica versus pós-verbal/enclítica), é possível constatar a produtividade de investigações no âmbito da percepção que objetivem correlacionar a interpretação dos enunciados por parte do ouvinte à caracterização não só do comportamento das variantes, mas também das variedades linguísticas. Duas pesquisas sobre a colocação dos pronomes oblíquos átonos contribuem para a verificação dessa suposta produtividade: Vieira (2002), 
Corrêa $(2009 ; 2012)$. Seus resultados, no tocante à percepção do estatuto prosódico dos clíticos e de sílabas átonas vocabulares, serão reunidos e confrontados neste artigo, a fim de ilustrar a importância de estudos que conjuguem resultados de produção aos de percepção.

As referidas pesquisas investigaram a cliticização pronominal em duas frentes de trabalho: (i) o tratamento variacionista do fenômeno por meio da análise de dados de entrevistas sociolinguísticas (variante pré-verbal, me dá, ou pós-verbal, dá-me, no caso de uma forma verbal, e posição do clítico antes da primeira, se pode dizer, entre a primeira e a segunda, pode se dizer, e após a segunda forma verbal, pode dizer-se, no caso de complexos); e (ii) a investigação acústica da ligação dos pronomes átonos (se à direita, em próclise, ou à esquerda, em ênclise), que, por sua vez, se desenvolveu por meio de dois instrumentos: a medição dos parâmetros acústicos do acento (duração, intensidade e frequência fundamental) de sílabas clíticas e vocabulares; e a ressíntese da fala (manipulação mecânica dos parâmetros no sinal de voz) associada ao julgamento dos enunciados por ouvintes do português brasileiro (PB).

No que se refere ao tratamento variacionista, podese afirmar brevemente, apenas para sinalizar tendências gerais, que clítico anteposto constitui preferência na fala brasileira quando se trata de construções com apenas uma forma verbal (me dá), ficando a realização pósverbal restrita a construções linguísticas particulares sobretudo com os clíticos $o$, $a(s)$ seguidos de infinitivo (encontrá-lo) e se em estruturas indeterminadoras (trata-se de.) - praticadas por grupos sociais com maior grau de escolaridade. No caso de construções com mais de uma forma verbal, o PB admitiria como opção preferencial a ordem intracomplexo verbal (que corresponde, na realidade, à "próclise" à segunda forma verbal, como em pode amanhã me dizer), ficando outras posições restritas a determinadas estruturas, como com o clítico se indeterminador antes da primeira (não se pode dizer...) ou ainda com o clítico $o, a(s)$ após a segunda forma no infinitivo (pode encontrá-lo) ${ }^{1}$. Dado o baixo índice de realização dessas estruturas e sua particularidade em termos qualitativos, os estudos sociolinguísticos da colocação acabam por postular a semicategoricidade da

\footnotetext{
Os resultados relativos a dados contemporâneos, de que se vale o presente artigo, confirmam, em certa medida, tendências propostas na vasta produção bibliográfica sobre o tema, cuja revisão não cabe nos propósitos limitados deste artigo. Vale destacar, aqui, que os estudos pioneiros da colocação pronominal não só apontaram as inovações brasileiras (Cf., por exemplo, PAGOTTO, 1992), mas também buscaram explicar fatores relacionados às motivações linguísticas, como as de natureza fonético-fonológica, demonstrando a correlação entre a ênclise e os pronomes com onset silábico (Cf. NUNES, 1998), e as sociais, como a vinculação da ênclise à fala monitorada de pessoas com alto nível de escolaridade (Cf. LOBO, 1992, MONTEIRO, 1994).
}

regra no PB (cf. VIEIRA, 2014) e não um comportamento efetivamente variável do fenômeno.

Quanto à caracterização da ligação fonética do clítico com um dos vocábulos que o circundam, os referidos estudos valem-se, sobretudo, da hipótese de que os clíticos brasileiros se comportariam prosodicamente como sílabas pretônicas, sendo estas mais proeminentes do ponto de vista acentual do que as postônicas. Para testar a validade dessa hipótese e assim melhor caracterizar o PB, Vieira (2002) e Corrêa $(2009,2012)$ desenvolveram fases semelhantes de investigação, que serão oportunamente descritas na seção metodológica deste artigo.

No âmbito do presente trabalho, objetiva-se, por meio da análise contrastiva dos resultados obtidos, demonstrar que dados relativos à percepção auditiva podem contribuir para a caracterização do comportamento de uma regra variável, considerando, no caso em questão, especificamente a ligação fonológica dos clíticos pronominais. A seguir, são sintetizados os fundamentos teóricos que deram respaldo às referidas análises. Depois, também em uma seção à parte, descrevem-se alguns experimentos realizados nas pesquisas, destacando-se os referentes à caracterização acústica e à ressíntese de fala associada à percepção dos indivíduos quanto aos enunciados submetidos a julgamento. Com base em todo o exposto, seguem aos resultados as considerações finais.

\section{Fundamentação teórica: a ligação fonológica dos clíticos}

A cliticização pronominal consiste na relação de dependência que os pronomes átonos mantêm com outros termos da oração. Klavans (1985), em trabalho de orientação formalista, caracterizou a cliticização e mostrou que as faces sintática e fonológica desse fenômeno podem ser abordadas de forma independente. Para tanto, a autora estabeleceu três parâmetros, aplicáveis a qualquer língua, os quais envolvem possibilidades binárias em que um clítico poderia se enquadrar.

De acordo com o primeiro parâmetro (dominância), um clítico pode ocorrer no início ou no final do constituinte dominante, de modo que fica assim definida, nesse estágio inicial, a instância estrutural a que se liga o clítico, qual seja seu hospedeiro sintático. No que se refere aos pronomes átonos do $\mathrm{PB}$, esse hospedeiro necessariamente é um verbo. Quanto ao segundo parâmetro (precedência), um clítico pode ocorrer antes ou depois do hospedeiro sintático, especificado pelo primeiro. Com base no parâmetro da precedência, verifica-se a variação na colocação pronominal, em que o clítico pode ocorrer antes ou depois da forma verbal. Valendo-se da linguagem formalista proposta por Klavans (1985), dominância e 
precedência correspondem a dois parâmetros de natureza sintática: o primeiro referente à relação entre o verbo e os clíticos na cadeia de ramificações; e o segundo, à disposição deles na perspectiva sintagmática da sentença.

O terceiro parâmetro (ligação fonológica), por outro lado, refere-se à direção para a qual um clítico (partícula átona) pode se projetar. Esse parâmetro vem mostrar que o hospedeiro fonológico do clítico não necessariamente coincide com seu hospedeiro sintático; além disso, evidencia que o caráter fonológico desses elementos átonos pode ser investigado separadamente das suas propriedades sintáticas, ainda que as duas faces estejam imbricadas. Nesse sentido, compreende-se por ligação fonológica a direção da projeção do clítico ao identificar o vocábulo morfológico adjacente em que ele se apoia para formar uma estrutura mais complexa na hierarquia prosódica.

Apesar de a observação dos componentes sintático e fonético-fonológico poder ocorrer de forma independente, as análises variacionistas realizadas por Vieira (2002) e Corrêa $(2009,2012)$, cujos resultados foram brevemente mencionados na introdução, colaboraram para o estudo da ligação fonológica. Construções sintáticas prototípicas na variedade brasileira, identificadas nas análises variacionistas, serviram de base para a investigação do parâmetro da ligação fonológica. Realizações como pode amanhã me dizer, em que houve, além do clítico, outro elemento interveniente ao complexo verbal, revelam que o pronome não assume estreita relação com a primeira forma verbal, sugerindo que essas partículas átonas, na posição interna ao complexo, assumiriam comportamento proclítico à segunda forma verbal. Assim sendo, análises fonéticas realizadas neste trabalho são baseadas em dados cuja configuração foi indicada a partir de análises das estruturas relativas à colocação pronominal. $\mathrm{O}$ terceiro parâmetro constitui, entretanto, tema central deste trabalho, que visa a investigar, com base na descrição acústica dos dados, a hipótese de que os pronomes átonos na variedade brasileira seriam geralmente proclíticos, e verificar, por meio da ressíntese de fala e dos testes de percepção auditiva, a interpretação brasileira do fenômeno e os elementos prosódicos que a determinam.

Ainda sobre fundamentos do presente trabalho, é importante fazer referência a Carvalho (1989). O autor estabelece uma comparação dos clíticos nas variedades brasileira e lusitana do português e, nesse processo, acaba por mostrar relevantes características relacionadas ao perfil das vogais das sílabas átonas nessas variedades. As características da colocação pronominal e do vocalismo foram abordadas com a finalidade de mostrar que as diferenças entre as variedades refletiriam o caráter enclítico dos pronomes na norma lusitana e proclítico na brasileira. De acordo com o autor, ainda que antepostos ao verbo, os pronomes átonos em Portugal se ligariam a um elemento à sua esquerda; no Brasil, por outro lado, os pronomes se ligariam a um elemento à sua direita. Essa hipótese ganha força no texto, fundamentada nas distinções feitas entre vogais pretônicas e postônicas.

Nesse sentido, a comparação entre os clíticos pronominais e as sílabas átonas constitui um recurso produtivo, tendo em vista que aqueles integram uma unidade vocabular fonológica quando se apoiam em uma palavra com acento, funcionando, assim, como uma sílaba do ponto de vista prosódico (cf. BISOL, 2005; e NESPOR; VOGEL, 1986). Embora a comparação seja plausível, é preciso atentar para o fato de que, na fronteira entre um clítico qualquer e o hospedeiro fonológico, pode ocorrer sândi externo, o que aproxima os clíticos do estatuto de palavra, como bem demonstram as autoras referidas, que chegam a propor um nível intermediário entre a palavra fonológica e a frase fonológica na hierarquia prosódica, chamado de grupo clítico. Guzzo (2015), em tese que discute a representação prosódica de estruturas com clíticos e compostos, defende a necessidade do constituinte Grupo Composto (VOGEL, 2008, 2009) entre a palavra fonológica e a frase fonológica. O clítico pronominal - cujo comportamento é contrastado por Guzzo (2015) aos clíticos não pronominais e aos prefixos átonos monossilábicos - estaria acomodado no nível Grupo Composto, apresentando por características particulares a elevação e o sândi vocálicos.

Em síntese, esses estudos, aqui brevemente referidos, corroboram a produtividade da estratégia de comparar sílaba clítica e sílaba vocabular, verificando se fenômenos típicos de fronteira entre palavras, como fusão e elisão, por exemplo, afetariam os clíticos pronominais, motivação que também orientou os experimentos que serão, a seguir, descritos.

\section{Procedimentos para a descrição acústica dos dados e a avaliação da percepção auditiva}

Tanto a pesquisa de Vieira (2002) quanto a investigação proposta em Corrêa (2009) envolvem basicamente dois tipos de experimentos: no primeiro, o procedimento consiste em medir, com o apoio de aparato técnico-computacional de análise acústica - CSL em Vieira (2002) e Praat em Corrêa (2009) -, os parâmetros de duração, intensidade e frequência fundamental (F0) relativos aos pronomes átonos e compará-los aos de uma sílaba pretônica; no segundo, a impressão/percepção auditiva que outras pessoas manifestam quanto à direção da ligação do pronome átonos é controlada, considerando enunciados com alteração dos parâmetros acústicos detalhadamente controlados por meio de ressíntese de fala - utilizando o programa CSL em Vieira (2002) e os programas Sound Forge e Praat em Corrêa (2009). 
Corrêa (2012), embora se assemelhe em seus objetivos e hipóteses às outras pesquisas já citadas, delas se diferencia nos seguintes aspectos: (i) observou, além de intensidade e duração, as frequências formânticas 1 e 2 (e não a F0), para que fosse possível o controle da qualidade vocálica em questão; (ii) valeu-se de tratamento estatístico (por meio do Programa $R$ ); e (iii) controlou detalhadamente o comportamento do pronome se, reflexivo ou indeterminador, para os quais tinha hipóteses particulares, como se mostrará adiante.

Assim sendo, o presente artigo contrasta os resultados obtidos nas etapas de investigação do tema desenvolvidas em equipe e divulgados nos trabalhos já citados. Dos dois primeiros, destaca-se a comparação entre a sílaba pretônica vocabular e a clítica, e do conjunto das investigações os resultados de percepção auditiva a partir de enunciados ressintetizados.

Para desenvolver a análise, as pesquisas partiram da formulação de enunciados, lidos e gravados do modo mais natural possível, em ambiente acusticamente isolado, por colaboradores da pesquisa na UFRJ (instituição promotora da investigação), todos do Rio de Janeiro e habituados a participarem de estudos de Fonética Experimental. Como o objetivo central da recolha dos dados se relacionava à descrição e à percepção da ligação fonológica (em relação à qual não se tinha por hipótese qualquer diferença relacionada ao perfil sociolinguístico quanto à idade e/ou sexo do informante), os indivíduos foram escolhidos pela referida experiência em gravações com naturalidade, experiência já atestada em outras oportunidades. Assim, apenas para melhor visualização dos indivíduos envolvidos em cada etapa de cada investigação, expõem-se, na tabela a seguir, as informações referentes aos indivíduos que colaboraram.

Tabela 1. Quantitativo de voluntários que participaram de cada uma das etapas das pesquisas por sexo e faixa etária

\begin{tabular}{|c|c|c|c|}
\hline & VIEIRA (2002) & CORRÊA (2009) & CORRÊA (2012) \\
\hline $\begin{array}{l}\text { Medição e } \\
\text { comparação } \\
\text { de parâmetros } \\
\text { acústicos }\end{array}$ & $\begin{array}{c}2 \text { mulheres entre } \\
20 \text { e } 30 \text { anos }\end{array}$ & $\begin{array}{l}3 \text { mulheres entre } \\
20 \text { e } 40 \text { anos }\end{array}$ & $\begin{array}{c}3 \text { homens entre } \\
20 \text { e } 30 \text { anos }\end{array}$ \\
\hline $\begin{array}{l}\text { Ressíntese } \\
\text { de fala }\end{array}$ & $\begin{array}{c}2 \text { mulheres entre } \\
20 \text { e } 30 \text { anos }\end{array}$ & $\begin{array}{c}2 \text { homens entre } \\
30 \text { e } 60 \text { anos }\end{array}$ & $\begin{array}{c}1 \text { homem entre } \\
50 \text { e } 60 \text { anos }\end{array}$ \\
\hline
\end{tabular}

A análise prosódica promovida por Vieira (2002) valeu-se, entre seus experimentos, de enunciados com cinco pares "homófonos"2 (me nino/menino; miçanga/me

\footnotetext{
2 Nem todos os pares eram homófonos legítimos; alguns apresentaram pequenas diferenças, como, por exemplo, no par o pago e opaco, em que ocorrem $[\mathrm{g}] \mathrm{e}[\mathrm{k}]$. Outra diferença recorrente nos pares diz respeito ao alteamento da vogal média dos clíticos, mas não da sílaba pretônica. Trata-se de limitações metodológicas que não inviabilizaram, mas foram consideradas na análise.
}

sangra; me dita/medita; te vê/TV; me ganha/meganha; te via/devia), formados por vocábulos com me e te como pronome átono e como sílaba pretônica (como em Só me nino na cadeira de balanço/Só menino na cadeira de balanço, ou Como miçanga acalma eu não entendo/ Como me sangra a alma eu não entendo).

Em Corrêa (2009), a análise dos pares "homófonos" proposta em Vieira (2002) é aprofundada. Foram criados mais 22 pares $^{3}$ e ampliou-se o contexto, para garantir maior naturalidade no momento da gravação, como em "Você agora me diz que o Thiago avisou que a reunião foi cancelada. Eu não lembro nada disso. Se ele me disse aquilo, eu saberia"/"Preciso que meçam esse muro, porque ele parece torto. Mas só tem um funcionário aqui "e acho que ele não sabe. Se ele medisse aquilo, eu saberia".

A comparação entre a sílaba clítica e a pretônica vocabular foi feita através da comparação dos respectivos "pesos fônicos". Estes correspondem a valores que traduzem o peso de cada parâmetro acústico das sílabas átonas em relação aos das suas sílabas circunvizinhas. Para calcular cada "peso fônico", procedeu-se ao cálculo da média aritmética dos valores das sílabas circunvizinhas e, em seguida, da fração da sílaba átona observada sobre essa média.

Por meio da comparação entre as referidas sílabas, as pesquisas puderam investigar a hipótese de que os parâmetros da duração e da intensidade atuariam juntos na constituição do acento relacionado às unidades estudadas. A F0 foi controlada nos experimentos porque era possível e tornava a análise mais completa, mas esperava-se que não houvesse diferenças significativas a esse respeito, pois a melodia das frases era neutra e este parâmetro afetaria o som em nível frasal, ou seja, seria determinante para mudar apenas o tipo de frase.

Quanto à ressíntese de fala associada a testes de percepção, desenvolvida nas três referidas pesquisas, os procedimentos apresentam algumas particularidades. Em Vieira (2002) e Corrêa (2009), as alterações nos clíticos foram feitas na mesma proporção; contudo, os enunciados utilizados não foram os mesmos. Vieira (2002) valeu-se dos enunciados ele vinha me comunicar o fato e tenho me visto cansado para manipulação das características da sílaba me no experimento de ressíntese de fala. Corrêa (2009) utilizou Eu mesma vinha me lavar antes de entrar na piscina e A Mirna vinha se lavar antes de entrar na piscina, enunciados nos quais foi possível alterar não só a sílaba me mas também a se.

\footnotetext{
3 me gera/megera; fez-me tal/fez metal; me ditar/meditar; me dissel medisse; me lava/melava; te ser/tecer; vendo-te armário/vendo tear, Mário; bem te vi/bem-te-vi; a tingiu/atingiu; a tiro/atiro; se lecional seleciona; se viciar/seviciar; se parou/separou; se cura/secura; se dar/ sedar; se senta/sessenta; se tenta/setenta; selava/selava; o pago/opaco; a pago/apago; a ver/haver.
} 
O procedimento de ressíntese de fala consistiu em formar novos enunciados em que o clítico tinha a intensidade e/ou a duração reduzida(s) de forma leve [30\% em Corrêa (2009), 50\% em Vieira (2002)] ou forte [50\% em Corrêa (2009), 70\% em Vieira (2002)], assim como poderia ter também a $\mathrm{F} 0$ reduzida em $20 \mathrm{~Hz}$, transformando o padrão entoacional de descendente para ascendente. Após as referidas manipulações, os estudos contaram com 11 enunciados alterados, mais duas vezes a versão original, totalizando 13 enunciados para julgamento. Cada sentença foi julgada quatro vezes por cinco juízes na pesquisa de Vieira (2002), enquanto na de Corrêa $(2009,2012)$ duas vezes por seis juízes.

Apesar de o hospedeiro fonológico do clítico não corresponder necessariamente a um verbo, o pronome controlado encontrava-se entre duas formas verbais, para atenuar uma possível influência da sintaxe sobre o julgamento, que deveria indicar se o clítico parecia estar ligado prosodicamente ao elemento anterior ou posterior a ele [vinha-se lavar ( ) ou vinha se-lavar ( )].

Corrêa (2012) refinou a proposta do experimento. Para tanto, modificou dois enunciados com a ressíntese de fala (você pode se dirigir ao balcão ao lado; pode-se dirigir a $80 \mathrm{~km}$ por hora), seguida da elaboração e aplicação de dois testes de percepção auditiva a 20 juízes, alunos da Pós-graduação da Faculdade de Letras/UFRJ.

Considerando a frase pode se dirigir ao balcão do lado, modificaram-se os parâmetros duração e/ou intensidade da vogal do clítico. Essas propriedades foram alteradas porque normalmente são responsáveis pelo acento em nível vocabular; então, reduzi-las significaria tornar a sílaba mais débil. A redução também podia ser "leve" ou "forte". Concernente à duração, a redução "leve" correspondia à diminuição de $30 \%$ do comprimento de onda da vogal, enquanto a redução "forte" correspondia à diminuição de $50 \%$. No que diz respeito à intensidade média, a redução "leve" correspondia a menos $3 \mathrm{~dB}$, enquanto a redução "forte", a menos $6 \mathrm{~dB}$.

Considerando o fragmento pode se dirigir, supôs-se que não só o clítico se, quando percebido como enclítico, é foneticamente débil, mas também o é a sílaba de, de pode, que corresponderia a uma sílaba átona nãofinal. Por isso, na ressíntese de fala, foram alteradas as propriedades da vogal do clítico, da vogal da sílaba de e de ambas simultaneamente. Para tanto, realizaram-se modificações diversas com reduções fortes $(6 \mathrm{~dB})$ e fracas $(3 \mathrm{db})$ da intensidade, fortes $(50 \%)$ e fracas $(30 \%)$ da duração, separadamente ou em conjunto. Da sentença gravada, pode se dirigir ao balcão do lado, o fragmento pode se dirigir alterado em 22 versões, além de quatro originais, sem qualquer alteração - tendo uma delas uma ligeira pausa entre pode e o clítico $s e$ - foi ouvido pelos juízes-ouvintes. Em cada teste, então, foram ouvidos 28 enunciados por um total de 20 pessoas. Antes de assinalar uma opção, cada juiz ouviu duas vezes o enunciado, fosse ele alterado ou original.

Além de as pessoas indicarem qual ligação julgavam compatível com a frase ouvida [pode-se dirigir/pode se-dirigir], deveriam, em uma outra audição das mesmas frases, indicar como completariam a frase [( ) a $80 \mathrm{~km}$ na cidade ( ) ao balcão do lado], demonstrando sua interpretação do enunciado a cada audição, se o clítico era de natureza indeterminadora (É possível dirigir/conduzir veículo a $80 \mathrm{~km}$ na cidade) ou reflexiva (Alguém pode se dirigir/encaminhar ao balcão do lado).

Por hipótese, em se tratando de se reflexivo, as frases originais seriam majoritariamente percebidas como ligação proclítica e o complemento seria "ao balcão do lado", conforme foi gravado originalmente. Consoante o aumento da fragilidade da vogal do clítico e/ou da sílaba postônica verbal $d e$, aumentaria a quantidade de julgamentos de clítico ligado ao primeiro verbo e do fragmento "ao balcão do lado". Como se pode observar, os testes de percepção em Corrêa (2012) buscaram averiguar a intuição de usuários da língua a respeito da ligação fonológica dos clíticos e de sua relação com propriedades sintáticas desses pronomes. Tomando por hipótese que os resultados dos testes confirmariam o que havia sido observado por meio das ondas sonoras, esperava-se que houvesse a identificação das reduções vocálicas do clítico e da sílaba final do verbo auxiliar como forte indicador de cliticização para a esquerda, configurando um caso de ênclise fonológica. Essa configuração acústica seria, ainda, compatível com a interpretação indeterminadora das construções com se, diferentemente da interpretação reflexiva, que configuraria um caso de próclise ao verbo temático.

Em síntese, o conjunto dos resultados destacados neste artigo permite observar, primeiramente, as propriedades acústicas de pronomes átonos e de sílabas pretônicas vocabulares, com as quais eles poderiam supostamente ser equiparados. Em um segundo momento, a partir do julgamento de enunciados originais e alterados, verificou-se o modo como ouvintes percebiam a ligação fonológica dos clíticos pronominais e, ainda, os parâmetros acústicos responsáveis por tal percepção.

\section{Descrição e análise dos resultados}

O estudo contrastivo dos resultados de Vieira (2002) e Corrêa $(2009,2012)$ permite comparar, nesta seção, (i) a duração e a intensidade dos pronomes átonos e das sílabas átonas correspondentes ${ }^{4}$, testando a hipótese de que o

\footnotetext{
4 Destacamos, neste artigo, as medições feitas em relação às sílabas me e te, em ambos os trabalhos, e ainda a sílaba $a$, apenas controlada em Corrêa $(2009,2012)$. Não apresentamos, nesta seção, os resultados relativos à $\mathrm{F} 0$ devido à sua natureza de distinção frasal, que não revelaria nada em específico sobre o estatuto da sílaba ora em estudo.
} 
caráter pretônico das sílabas em análise seria proveniente da atuação desses dois parâmetros em parceria; e (ii) as respostas aos testes de percepção auditiva quanto à ligação fonológica dos enunciados após a ressíntese de fala.

\section{Os pronomes átonos e a caracterização acústica: sílaba pretônica?}

Tendo em vista o detalhamento dos índices resultantes das medições dos parâmetros acústicos em todos os enunciados contemplados, apresenta-se aqui tãosomente a síntese dos resultados, com base nos quais foi possível eleger as medidas posteriormente adotadas nas manipulações da ressíntese da fala.

No que se refere ao comportamento da intensidade de acordo com os dados de Vieira (2002), o "peso fônico" do pronome e da sílaba pretônica vocabular não destoou mais que dois pontos percentuais em praticamente todos os casos. Dessa forma, esses resultados preliminares parecem confirmar o paralelismo entre pronomes átonos e sílabas pretônicas vocabulares, permitindo afirmar que, de acordo com o parâmetro da intensidade, os clíticos pronominais, na variedade brasileira, se ligariam a um elemento à sua direita (próclise).

Considerando os dados controlados por Corrêa (2009), verificou-se que, da mesma forma que em Vieira (2002), as diferenças entre sílaba clítica e pretônica vocabular não são expressivas quanto à intensidade. Excetuando-se um par na fala de apenas uma informante, os enunciados comparados enquadram-se na margem de apenas dois pontos percentuais de diferença.

Sobre a duração, os resultados de Vieira (2002) demonstraram que as diferenças entre as sílabas não ultrapassam dez pontos percentuais, o que permite afirmar que os dois tipos de sílabas se assemelham também do ponto de vista desse parâmetro. Acredita-se que as diferenças um pouco maiores no controle da duração do que no da intensidade decorram da qualidade vocálica presente nas sílabas em análise. Na realidade, a vogal média do pronome normalmente é alteada, ao contrário da vogal da sílaba pretônica vocabular, o que provavelmente seria o fator responsável pelas diferenças registradas. Essa hipótese é fortalecida pelos valores quase idênticos envolvendo o par me sangra/miçanga; neste caso, os valores todos seriam referentes a um $i$ - alteado no primeiro caso, subjacente no segundo.

Os resultados em Corrêa (2009) para a duração demonstram ora diferença, ora semelhança entre a sílaba clítica e a pretônica vocabular. Entretanto, considerando os três únicos pares efetivamente homófonos, nota-se semelhança entre as referidas sílabas também em relação à duração (com exceção do par bom a ver/bom haver).
Não obstante a particularidade das ocorrências controladas em Vieira (2002) e Corrêa (2009), os resultados obtidos trazem evidências da existência de certo paralelismo entre um tipo e outro de sílaba. Nesse sentido, sem dúvida, os índices oriundos da percepção auditiva a partir dos enunciados da ressíntese de fala poderão complementar esses resultados e, assim, colaborar para a compreensão da ligação fonológica dos pronomes átonos na variedade brasileira.

Em Corrêa (2012), o conjunto de resultados revelou, na maioria das vezes, semelhança entre a vogal dos pronomes átonos e das sílabas átonas vocabulares/ lexicais, especialmente quando se tratava de vogal alta, em total paridade segmental. As diferenças significativas observadas decorreram, sobretudo, de propriedades intrínsecas às vogais mensuradas. Dentre os pronomes investigados em uma primeira etapa - me, te e se (reflexivo e indeterminador) -, o se em estrutura indeterminadora apresentou, por vezes, resultados inesperados, o que levou ao entendimento de que esse pronome possui um comportamento diferenciado em relação ao do se reflexivo.

Em comparações que visavam descrever especificamente os referidos tipos de se, os resultados mostraram que a ligação fonológica dessa forma pronominal é instável. Ora há indícios de uma ligação proclítica, ora de uma ligação enclítica. Intuitivamente, a ligação enclítica é associada à ligação sintática que se indeterminador estabelece com o verbo auxiliar (pode-se dirigir), enquanto a proclítica é associada à ligação sintática que se reflexivo estabelece com o verbo temático (pode se-dirigir). Todavia, a observação dos parâmetros acústicos não demonstra com clareza essa intuição dos falantes, mas aponta indícios de que esses pronomes podem apresentar comportamento variável quanto ao chamado parâmetro de ligação fonológica.

De modo geral e considerando as pesquisas aqui contempladas, pode-se afirmar, a título de sistematização, que existem fortes indícios de que o clítico pronominal na variedade brasileira do Português seja prototipicamente proclítico. Houve semelhanças entre sílaba clítica e sílaba pretônica vocabular tomando por base os parâmetros acústicos de duração e intensidade, semelhanças não tão evidentes no caso do pronome se e em pares com diferença na qualidade vocálica.

\section{Cliticização e testes de percepção auditiva: ligação à direita?}

Embora sejam subjetivos os julgamentos em um teste de percepção, tendo em vista as sutis diferenças entre várias das sentenças em análise, os resultados das pesquisas revelaram tendências equivalentes, o que 
assegura, pelo controle fino da qualidade dos enunciados, haver interpretações partilhadas pelos juízes-ouvintes. A fim de ilustrar a proporção dos votos quanto à ligação fonológica, mostram-se, a seguir, os percentuais obtidos para os enunciados vinha me comunicar, de Vieira (2002), quanto à ligação assinalada em cada enunciado manipulado.

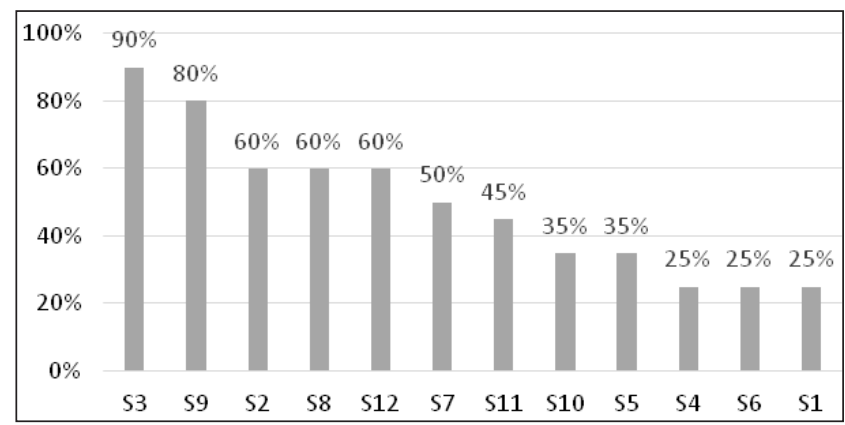

Gráfico 1. Percentuais de votos conferidos à ligação do pronome à primeira forma verbal (ênclise) segundo Vieira (2002, p. 378): enunciado original (s1) e enunciados manipulados na ressíntese da fala (s2 a s10) ${ }^{5}$

Os pronomes foram interpretados como proclíticos principalmente nos enunciados originais ou alterados da seguinte forma: somente a F0 modificada ou redução leve da intensidade. Com a redução forte da intensidade, a quantidade desses votos diminui; porém, o que realmente provoca a mudança de interpretação sobre a ligação do pronome parece ser a redução da duração. A redução forte desta, combinada ou não com outro tipo de modificação, fez aumentar significativamente a interpretação enclítica do pronome.

Essas mesmas tendências podem ser observadas nos resultados obtidos em Corrêa (2009) sobre o enunciado vinha me lavar. $\mathrm{O}$ pronome me foi interpretado como proclítico majoritariamente quando o enunciado se encontrava na versão original, bem como quando a F0 foi alterada e/ou a intensidade. Conforme ocorre a redução forte da intensidade e/ou leve da duração, acrescidas ou não da modificação da $\mathrm{F} 0$, os votos assumem caráter neutro, demonstrando dúvida dos juízes. A mudança de interpretação da ligação do clítico acontece nos mesmos contextos apontados em Vieira (2002).

\footnotetext{
5 As alterações dos parâmetros realizadas das sentenças 2 a 10, visto que a 1 é a original, são as seguintes: S2 = redução 'leve' da duração; S3 = redução 'forte' da duração; S4 = redução 'leve' da intensidade; $\mathrm{S} 5$ = redução 'forte' da intensidade; S6 = F0 ascendente; S7 = redução 'leve' de duração e intensidade; S8 = redução 'leve' da duração e 'forte' da intensidade; S9 = redução 'forte' da duração e 'leve' da intensidade; $\mathrm{S} 10=\mathrm{F} 0$ ascendente e redução 'leve' da duração; $\mathrm{S} 11=\mathrm{F} 0$ ascendente e redução 'leve' da intensidade; S12 = F0 ascendente e redução 'leve' de duração e intensidade.
}

Apesar da instabilidade natural dos votos em experimentos dessa natureza, em que até mesmo nos enunciados originais não se detecta categoricidade, deve-se registrar que houve extremos bem nítidos, indicando que as pessoas percebem o pronome como ligado ao elemento à sua direita e, conforme se alteram a duração e intensidade, essa percepção tende a mudar. Com a complementação dos resultados de ressíntese da fala, fica mais evidente o papel não só da intensidade, mas também da duração na composição do estatuto acentual dos pronomes átonos.

Em síntese, em Corrêa (2009), os resultados, relativos tanto ao pronome me (quanto ao se), convergem para a conclusão sistematizada na Figura 1.

\begin{tabular}{|c|c|c|}
\hline \multicolumn{3}{|c|}{ + Próclise / - ênclise $\longrightarrow$ - Próclise / + ênclise } \\
\hline $\begin{array}{l}\text { Versão original, } \\
\text { F0 ascendente e/ou } \\
\text { redução "leve" } \\
\text { da intensidade. }\end{array}$ & $\begin{array}{l}\text { Redução "forte" } \\
\text { da intensidade e/ou } \\
\text { redução "leve" } \\
\text { da duração, } \\
\text { combinada(s) ou não } \\
\text { à F0 ascendente. }\end{array}$ & $\begin{array}{l}\text { Redução "forte" } \\
\text { da duração el } \\
\text { ou redução "leve" } \\
\text { da intensidade, } \\
\text { combinadas ou não } \\
\text { à F0 ascendente. }\end{array}$ \\
\hline
\end{tabular}

Fonte: Corrêa (2009, p. 937).

Figura 1. Representação escalar dos resultados dos testes de percepção auditiva de Corrêa $(2009)^{6}$

Sem dúvida, dada a complexidade do fenômeno, é fato que nem sempre os valores referentes às medidas prosódicas devem condizer com a impressão resultante da percepção auditiva. Buscando refinar a análise da percepção, observam-se, a seguir, os resultados fornecidos por Corrêa (2012), primeiramente os dos testes perceptivos, para averiguar a direção da ligação do pronome se, gravado inicialmente com noção reflexiva (alguém pode se dirigir ao balcão do lado).

A percepção foi majoritariamente de ligação proclítica nas duas vezes em que as versões originais de pode se dirigir foram apresentadas, especialmente aquela contendo uma pausa entre o pronome se reflexivo e o primeiro verbo (V1). Desse modo, além da coerência entre os votos em relação às versões da frase originalmente gravada, a ligação de se reflexivo mostrou-se proclítica quando ele se encontra no interior de uma locução. Considerando as vinte e duas versões da ressíntese de fala (cf. Gráfico 2), é apresentada a quantidade de votos registrados de clítico se ligado a V1 (ênclise).

Os enunciados alterados estão dispostos por ordem crescente de expectativa de votos de pronome ligado a V1. Os oito primeiros referem-se às sentenças em que se

\footnotetext{
${ }^{6}$ A linha tracejada pretende representar o limite tênue entre as duas categorias.
} 


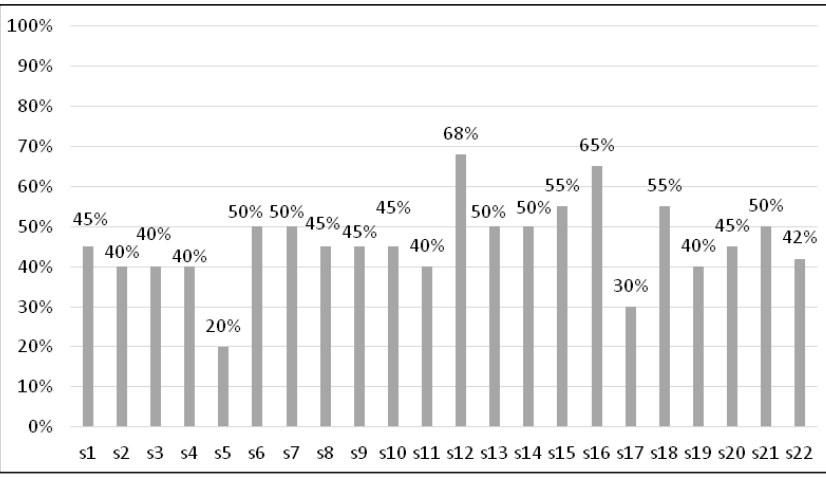

Gráfico 2. Percentuais de votos conferidos à ligação do clítico se à primeira forma verbal (ênclise) segundo Corrêa (2012, p. 229): enunciados manipulados na ressíntese da fala $\left(\mathrm{s} 1\right.$ a s22) ${ }^{7}$

modificou apenas a vogal da sílaba postônica de pode. Os oito seguintes referem-se às sentenças em que se modificou a vogal do pronome. Os demais enunciados abarcam alterações feitas tanto na vogal da sílaba de quando na do pronome se. Em cada subconjunto, a redução forte da duração em primeiro plano, associada secundariamente à redução da intensidade, estaria entre os contextos mais cotados para a percepção de ênclise, conforme indicam os resultados de Vieira (2002) e Corrêa (2009). A gradação estabelecida, todavia, não se confirmou realmente. $\mathrm{Na}$ maioria dos contextos controlados, os votos variaram sutilmente. Apesar disso, conforme revelam os resultados, a hipótese que estava por trás da hierarquia - quanto menor a energia acústica do clítico, maior a percepção de ênclise - pôde ser confirmada.

Considerando s1 a s8, o máximo de votos de ênclise registrado foi $50 \%$. Neste caso, tratava-se de enunciado cuja redução foi forte da duração (s6) e daquele em que esta foi combinada à redução fraca da intensidade (s7).

\footnotetext{
7 As alterações dos parâmetros realizadas das sentenças s1 a s22 são as seguintes: $\mathrm{S} 1$ = redução 'fraca' da intensidade da vogal de $d e ; \mathrm{S} 2=$ redução 'fraca' da duração da vogal de $d e ;$ S3 = redução 'fraca' da duração $\mathrm{e}$ da intensidade da vogal de $d e ; \mathrm{S} 4$ = redução 'forte' da intensidade da vogal de de; $\mathrm{S} 5$ = redução 'fraca da duração e 'forte' da intensidade da vogal de $d e ; \mathrm{S} 6$ = redução 'forte' da duração de $d e ; \mathrm{S} 7$ = redução 'forte' da duração e 'fraca' da intensidade da vogal de $d e ; \mathrm{S} 8$ = redução 'forte' da duração e da intensidade da vogal de de; S9 = redução 'fraca' da intensidade da vogal de $s e ; \mathrm{S} 10$ = redução 'fraca' da duração da vogal de se; $\mathrm{S} 11$ = redução 'fraca' da duração e da intensidade da vogal de se.; $\mathrm{S} 12=$ redução 'forte' da intensidade da vogal de $s e ; \mathrm{S} 13=$ redução 'fraca' da duração e 'forte' da intensidade da vogal de se; S14 = redução 'forte' da duração da vogal de $s e ; \mathrm{S} 15$ = redução 'forte' da duração e 'fraca' da intensidade da vogal de se; S16 = redução 'forte' da duração e da intensidade da vogal de se; S17 = redução 'fraca' da intensidade da vogal de de e da vogal de se; S18 = redução 'forte' da intensidade da vogal de de e da vogal de se; S19 = redução 'fraca' da duração da vogal de de e da vogal de se; S20 = redução 'forte' da duração da vogal de de e 'forte' da intensidade da vogal de se; S21 = redução 'forte' da intensidade da vogal de de e 'forte' da duração da vogal de se; S22 = redução 'forte' da duração da vogal de de e redução 'forte' da duração da vogal de se. Duas sentenças julgadas não apresentam porcentagens múltiplas de cinco, em virtude de um juiz não ter assinalado uma das opções (ênclise ou próclise), passando o total de votos de vinte para dezenove.
}

Mesmo com redução forte da intensidade, os votos referentes a clítico ligado a V1 foram poucos; entretanto, quando se passou de redução fraca da duração para forte, combinada ou não à alteração da intensidade, os votos para a ênclise aumentaram.

Quando somente a vogal do pronome foi alterada (s9 a s16), registraram-se as maiores porções de votos de pronome enclítico: $68 \%$ dos votos quando houve redução forte da intensidade da vogal (s12) e $65 \%$ quando houve redução forte da duração e intensidade (s16). Diferentemente do que demonstram os resultados relativos aos enunciados cuja vogal da sílaba de foi modificada, a redução forte da intensidade foi comum entre os dados com maior quantidade de pessoas que perceberam ênclise. Acima de $50 \%$, correspondendo a $55 \%$, está também o enunciado com redução forte da duração e fraca da intensidade (s15), o mesmo tipo de alteração que se destacou dentre as sentenças cuja vogal da sílaba postônica $d e$ foi manipulada.

Levando em consideração a sutileza na diferenciação entre estruturas enclíticas a V1, supostamente indeterminadoras, e proclíticas a V2, supostamente reflexivas, assume-se que são muito reveladores os índices superiores à metade dos votos. A maioria dos informantes, não obstante à grande dificuldade de reconhecimento dos padrões, admite haver alteração de direção fonológica exatamente quando ocorre uma forte redução do(s) parâmetro(s) acústico(s) do acento.

Associando os resultados referentes aos dois grupos de enunciados (alterações exclusivas na sílaba de e alterações exclusivas na sílaba do pronome), a percepção dos juízes revela que a alteração da direção fonológica, ao que tudo indica, depende de reduções significativas (e não leves) da duração e/ou da intensidade, sobretudo na sílaba referente ao pronome átono.

Cabe, ainda, analisar o terceiro subconjunto de dados, em que não só a vogal da sílaba postônica do verbo auxiliar pode, mas também a do clítico se foi alterada (s17 a s22). A hipótese de que, nesse caso, aumentariam os votos de ênclise não foi confirmada na totalidade dos enunciados; os votos referentes à ligação fonológica para a esquerda estão entre $30 \%$ e $55 \%$. O menor desses índices corresponde ao enunciado com redução fraca da intensidade da vogal da sílaba de e do pronome se (s17). O maior dos índices, por sua vez, superior à metade dos votos, corresponde ao enunciado com redução forte da intensidade da vogal da sílaba de e do se (s18). Nos dois casos, está em jogo o parâmetro intensidade, sendo que os dois índices mais altos, mais uma vez, se referem a reduções fortes, enquanto os dois mais baixos se referem a reduções fracas.

Observando o Gráfico 2 como um todo, nota-se que a frequência dos votos revela que, na maioria das vezes, 
a percepção de ênclise está concentrada entre $40 \%$ e 55\%. Apenas quatro enunciados apresentam uma frequência que ultrapassa essas margens: redução fraca da duração e forte da intensidade da vogal de de $(20 \%)$, redução fraca da intensidade da vogal da sílaba de e do pronome se $(30 \%)$, redução forte da intensidade da vogal de se $(68 \%)$, e redução forte da duração e intensidade da vogal de se $(65 \%)$

Associando esses valores à análise detalhada que se fez acerca do aumento ou da diminuição do número de votos em cada subconjunto dos dados, as propriedades do clítico, referentes à intensidade e à duração, ora conjugadas, ora não, são responsáveis por estabelecer a ligação enclítica ou proclítica. Destacando os índices de votos superiores a $50 \%$ para ênclise, que revelariam a mudança de percepção dos ouvintes - da próclise a V2 à ênclise a V1 -, a intensidade parece demonstrar papel mais proeminente do que a duração.

Os resultados de Corrêa (2012) não mostram com clareza o papel individual da duração e da intensidade sobre o fenômeno. Possivelmente o tipo de clítico justifica a maior clareza nos resultados de Vieira (2002) e Corrêa (2009), se comparados aos de Corrêa (2012). O pronome se, não só por sua constituição segmental, mas também por sua distinção significativa (indeterminador versus reflexivo), comporta-se como o clítico que demonstra de forma menos saliente as diferenças acústicas. Não obstante essas dificuldades, este estudo permite verificar que não se trata da duração somente ou da intensidade o fator de determinação da ligação enclítica ou proclítica, mas da concorrência dos parâmetros acústicos. Independentemente de se ter destacado o parâmetro duração ou intensidade, os resultados dos três trabalhos mostram que, quanto menos evidente (mais débil) é o pronome átono (mais do que a sílaba final do verbo, como o de em pode), mais frequente é o reconhecimento de ênclise. Dessa forma, o pronome breve e/ou fraco é entendido, em certa medida, como ligado à primeira forma verbal.

Os resultados do segundo teste de percepção aplicado por Corrêa (2012) confirmam a relação entre a cliticização fonológica e os tipos de pronome se (se reflexivo ou indeterminador). A ligação proclítica percebida nas versões originais da frase gravada foi associada ao clítico se reflexivo; fato evidenciado, sobretudo, quando o enunciado apresentava uma ligeira pausa entre o verbo auxiliar e o pronome, de modo que não restasse dúvida sobre a ligação fonológica. Ademais, a interpretação do pronome passou a ser indeterminadora principalmente quando a vogal do pronome tinha sido reduzida, o que revelou mudar a percepção da cliticização fonológica.

Conforme se esclareceu na metodologia deste trabalho, no teste sobre a interpretação do tipo de pronome se, os juízes deveriam optar por um complemento para o fragmento pode se dirigir (a $80 \mathrm{~km}$ na cidade ou ao balcão do lado). Os resultados seguem expostos no Gráfico 3.

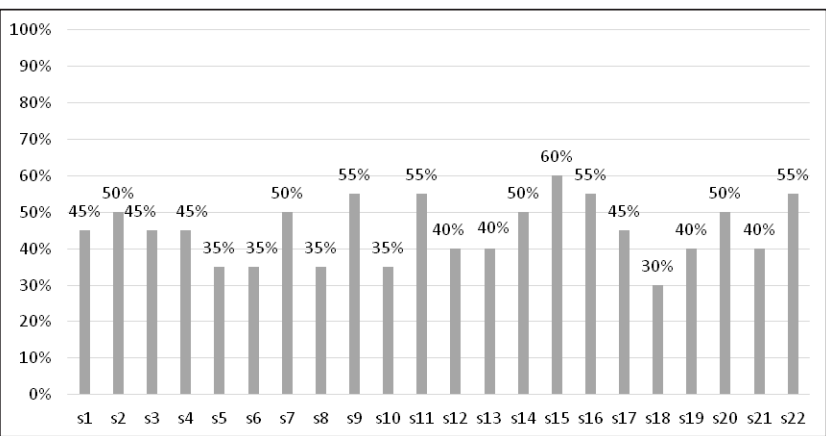

Gráfico 3. Percentuais de votos conferidos à ligação do clítico se indeterminador segundo CORRÊA (2012, p. 236): enunciados manipulados na ressíntese da fala (s1 a s22) ${ }^{8}$

A análise desses resultados centrou-se no número de sujeitos que interpretaram o enunciado como uma estrutura indeterminadora. Desse modo, pretendeu-se identificar os elementos que causaram ou não essa percepção. Podese perceber, a partir dos resultados apresentados, que a oscilação na votação ocorreu principalmente quando estava em jogo o estatuto fonético do pronome átono.

Quando somente a vogal da sílaba postônica do verbo auxiliar pode havia sido alterada, os votos que indicavam se indeterminador foram medianos (em torno de $50 \%$ ) ou pouco expressivos $(35 \%)$, o que sugere considerável dúvida no julgamento ou comportamento indiferente dessa sílaba frente à realização do pronome se. Quando a maioria das pessoas assinalou a opção relativa à estrutura indeterminadora, os enunciados estavam envolvidos normalmente com redução forte, sobretudo, da duração. Dentre cinco dados com mais de $50 \%$, apenas dois se referem à redução fraca (da intensidade somente e combinada à redução também fraca da duração). Assim, quanto mais debilitado o pronome se, maior sua associação com o tipo indeterminador, da mesma forma que a redução da duração e/ou intensidade foi relacionada à ligação enclítica ao verbo auxiliar.

Assim sendo, consideradas as dificuldades naturais inerentes ao experimento e aquelas referentes ao uso exclusivo do pronome se, já comentadas, a oscilação dos votos no teste relativo à interpretação do clítico, no limite máximo de $60 \%$, confirma a hipótese básica da investigação: a de que o comportamento fonético dos dados quanto à ligação fonológica atua para a distinção entre os clíticos, que a sintaxe mostra de forma inequívoca.

\footnotetext{
8 As alterações feitas obedecem à mesma sequência apresentada no Gráfico 2, descritas na Nota de rodapé no 7.
} 


\section{Considerações finais}

Os resultados contrastados neste trabalho permitiram verificar a hipótese de que a sílaba clítica na variedade brasileira se assemelharia a uma sílaba pretônica vocabular do ponto de vista prosódico. Os experimentos apresentados - de percepção e de produção em conjunto - colaboraram significativamente para a confirmação da hipótese de modo geral, embora não totalmente aplicável a depender do tipo de clítico. É importante, nesse sentido, perceber que a metodologia ora experimentada, ao evidenciar as características básicas de cliticização na variedade brasileira (sociofonéticas, por assim dizer), constitui, ao que tudo indica, forte auxílio aos estudos sociolinguísticos que objetivam definir as características de cada variedade do português.

Com base no conjunto das medições e dos testes de percepção após a ressíntese da fala, o reconhecimento da ênclise e a interpretação do se como indeterminador ocorrem geralmente quando a vogal do clítico tem sua duração e/ou intensidade fortemente reduzida(s). Dessa forma, os resultados foram ao encontro da hipótese de que o se reflexivo, em posição interna ao complexo verbal, se ligaria procliticamente ao verbo temático (o que é característico do Português do Brasil), ao passo que o se indeterminador se ligaria encliticamente ao verbo auxiliar (o que não diferenciaria fortemente o Português do Brasil e o Europeu). Em síntese, quanto mais nítida a fragilidade acentual do clítico, mais ele foi interpretado como enclítico e como se indeterminador.

Espera-se que os resultados apresentados no presente artigo possam ter demonstrado a eficiência da conjugação dos estudos de descrição, sociolinguística ou acústica, de dados oriundos da produção linguística aos da percepção acerca dos usos - auxiliada nos experimentos pelo recurso da ressíntese da fala. Ao que tudo indica, resultados dessa natureza constituem evidências de que é preciso investir cada vez mais em investigações que contemplem a percepção linguística, não só no plano da ordem dos clíticos pronominais, mas em uma diversidade de fenômenos linguísticos.

\section{Referências}

BISOL, Leda. Os constituintes prosódicos. Introdução a estudos de fonologia do português brasileiro. 4. ed. Porto Alegre: EDIPUCRS, 2005. p. 243-255.

CARVALHO, Joaquim Brandão de. Phonological conditions on Portuguese clitic placement: on syntactic evidence for stress and rhythmical patterns. Linguistics, v. 27, p. 405-436, 1989.

CORRÊA, Cristina Marcia Monteiro de Lima. Cliticização fonológica em variedade brasileira do português. In: HORA,
Dermeval (Org.). ABRALIN 40 anos em cena. João Pessoa: da UFPB, 2009. p. 932-938.

CORRÊA, Cristina Marcia Monteiro de Lima. Cliticização pronominal na região metropolitana do Rio de Janeiro: a interface Sintaxe-Fonologia. 2012. 278 f. Dissertação (Mestrado em Língua Portuguesa) - Faculdade de Letras, Universidade Federal do Rio de Janeiro, Rio de Janeiro, 2012.

GUZZO, Natália Brambatti. A prosodização de clíticos e compostos em português brasileiro. 2015. $232 \mathrm{f}$. Tese (Doutorado em Letras) - Instituto de Letras, Universidade Federal do Rio Grande do Sul, Porto Alegre, 2015.

KLAVANS, Judith. The independence of Syntax and Phonology in cliticization. Language, v. 61, p. 95-120, 1985.

LOBO, Tânia. A colocação dos clíticos em Português: duas sincronias em confronto. 1992. 238 f. Dissertação (Mestrado em Linguística) - Faculdade de Letras, Universidade de Lisboa, Lisboa, 1992.

MONTEIRO, José Lemos. Pronomes pessoais: subsídios para uma gramática do português do Brasil. Fortaleza: Edições UFC, 1994.

NESPOR, Marina; VOGEL, Irene. Prosodic phonology. Dordrecht: Foris Publications, 1986.

NUNES, Jairo. Direção de cliticização, objeto nulo e pronome tônico na posição de objeto em Português Brasileiro. In: ROBERTS, Ian; KATO, Mary (Org.). Português brasileiro: uma viagem diacrônica. Campinas: Editora da UNICAMP, 1996. p. 207-222.

PAGOTTO, Emílio Gozze. A posição dos clíticos em Português: um estudo diacrônico. 1992. 179 f. Dissertação (Mestrado em Linguística) - Instituto de Estudos da Linguagem, Universidade Estadual de Campinas, Campinas, 1992.

VIEIRA, Silvia Rodrigues. Colocação pronominal nas variedades europeia, brasileira e moçambicana: para a definição da natureza do clítico em Português. 2002. $441 \mathrm{f}$. Tese (Doutorado em Letras Vernáculas) - Faculdade de Letras, Universidade Federal do Rio de Janeiro, Rio de Janeiro, 2002.

VIEIRA, Silvia Rodrigues. Entre o variável e o categórico: a concordância verbal e a colocação pronominal em variedades do Português. In: REZENDE, Letícia et al. (Org.). A interdisciplinaridade e a especificidade linguística: teorias e práticas. Araraquara; FCL-UNESP Laboratório Editorial; Séries Trilhas Linguísticas, n. 26, São Paulo: Cultura Acadêmica, 2014. p. 75-98.

VOGEL, Irene. The morphology-phonology interface: isolating to polysynthetic languages. Acta Linguistica Hungarica, v. 55, p. 205-226, 2008.

VOGEL, Irene. The status of the Clitic Group. In: GRIJZENHOUT. Janet; KABAK, Baris (Ed.). Phonological domains: universals and deviations. Berlin: Mouton de Gruyter, 2009. p. $15-46$

Recebido: 15 de setembro de 2016

Aprovado: 10 de março de 2017

Contatos: silviavieira@hotmail.com cmarciamlc@hotmail.com 